\title{
Blue and UV LED-induced fluorescence in cotton foreign matter
}

\author{
Adnan Mustafic ${ }^{1}$, Changying $\mathrm{Li}^{i^{*}}$ and Mark Haidekker ${ }^{2}$
}

\begin{abstract}
Background: Cotton is an important domesticated fiber used to manufacture a variety of products and industrial goods. During harvesting with cotton strippers and cotton pickers, it is contaminated with foreign matter from botanical and non-botanical sources which adversely affect the quality and consistency of cotton, and therefore reduces its market value. To improve the current grading done by the High Volume Instrument (HVI) and human inspectors, it was explored whether fluorescence imaging can be used for cotton foreign matter detection.

Results: Eight types of botanical foreign matter (bark, bract, brown leaf, green leaf, hull, seed coat, seed, stem), and four types of non-botanical foreign matter (paper, twine, plastic bale packaging, plastic bag) were subjected to a fluorescence spectroscopy analysis to determine their optimal excitation and emission wavelength range. Matrix 3D scans were performed in the excitation range from $300 \mathrm{~nm}$ to $500 \mathrm{~nm}$, and emission range from $320 \mathrm{~nm}$ to $700 \mathrm{~nm}$, and the results indicated the photo-excitable fluorescence in the aforementioned excitation range for all the selected foreign matter categories. Consequently, the blue and the UV LEDs were selected as the excitation sources. The blue LED light provided optimal excitation light for bark, brown leaf, bract, green leaf, hull, and stem, while the UV LED light provided optimal excitation light for paper, plastic bag, plastic packaging, seed, seed coat, and twine.

Conclusions: UV and blue light induces fluorescence in 12 types of botanical and non-botanical cotton foreign matter. An imaging apparatus with blue and UV light excitation sources, and a consumer grade SLR camera was successfully developed to capture and characterize fluorescent images of cotton foreign matter. Based on the results, fluorescent imaging could be a promising method for cotton foreign matter detection. Future studies will focus on the classification of cotton foreign matter categories and to further refine the image processing sequence.
\end{abstract}

Keywords: Cotton foreign matter, Fluorescence, Spectroscopy, Blue LED, UV LED, Imaging

\section{Background}

Cotton is the most important natural fiber in the world. Worldwide in 2004, 40\% of fiber utilized was cotton, with end products including clothes, home furnishings, industrial products, and food [1]. Food from cotton byproducts includes cottonseed oil, while seed and hull are used to produce animal feed. In the United States, cotton is harvested with cotton pickers and strippers, while in the rest of the world, cotton is primarily harvested by manual labor [1]. One challenge is the introduction of foreign matter to the harvested seed cotton, which is picked up

\footnotetext{
*Correspondence: cyli@uga.edu

${ }^{1}$ College of Engineering, University of Georgia, 712F Boyd Graduate Research and Studies Center, 30602 Athens, GA, USA

Full list of author information is available at the end of the article
}

both by human pickers and harvesting machines. The foreign matter, considered to be trash, can be separated into two groups based on their respective origin: botanical and non-botanical foreign matter. Botanical foreign matter (e.g. bark, bract, brown leaf, green leaf, hull, seed coat, seed, stem) originates from cotton plants or other nearby plants, while non-botanical foreign matter is typically brought to the field from elsewhere. The amount of foreign material in cotton is one of the most important cotton quality parameters, even more so when the cotton-processing equipment becomes more automatic. The presence of foreign matter in cotton severely affects cotton grade and thus the price per bale paid by the spinner to cotton growers [2]. In addition, the foreign matter in cotton also reduces the efficiency of the spinning 
and ginning operations, and eventually lowers the quality of the final woven product. Therefore, rapid identification and classification of the foreign matter in cotton at each stage of cleaning and processing is important to eliminate or reduce the presence of trash and improve ginning/spinning efficiency and quality. Currently, cotton foreign matter grading is performed by human classers and instruments, such as the High Volume Instrument (HVI). Grades assigned by human classers are subjective, and more accurate grading is performed by the grading instruments. The HVI utilizes the geometric method to acquire images of the surface of cotton samples, and it estimates the area occupied by foreign matter, but lacks specificity as to the type of foreign matter detected [3].

Typically, spectroscopic and imaging methods have been used to detect and differentiate cotton foreign matter. A study by Himmelsbach et al. used Fourier Transform-Infrared (FT-IR) spectroscopy combined with Attenuated Total Reflectance (ATR) to retrieve the spectra of distinct cotton foreign matter categories from botanical and non-botanical sources, and compare it to the spectra in the reference database [4]. Spectral matching of reference spectra and sample spectra was observed between Pima cotton foreign matter and Upland cotton foreign matter. The accuracy diminished when samples consisted of a mixture of cotton varieties, and a mixture of experimental varieties, thus necessitating a continuous update of the reference database spectral content.

Fortier et al. used FT-Near-Infrared (FT-NIR) spectroscopy to obtain spectra from four botanical cotton foreign matter categories (hull, leaf, seed coat, stem) and compare them to the spectra from the reference database [5]. The results show a $97 \%$ foreign matter category prediction accuracy with those found in the reference set, but it needs to be renewed periodically with the reference spectra from new cultivars. A study by the same research group acquired the unique spectral signatures of botanical (hull, leaf, seed, seed coat, stem) and non-botanical (various types of polyethylene and polypropylene plastics) foreign matter in the wavelength range from 800-2500 $\mathrm{nm}[6]$. The aforementioned spectra were compared to the spectra present in the NIR spectral database, resulting in the overall accuracy of $98 \%$. The results could be further improved with the addition of spectra from other types of foreign matter.

Liu et al. attempted classification of seven leaf categories of cotton with a research grade spectrometer [7]. Classification models were developed by employing the soft independent modeling of class analogy (SIMCA) and principal component analysis (PCA). Subsequent application on 650 cotton lint samples with different leaf grades resulted in classification rates ranging from $86 \%$ for the spectral region of $405-1095 \mathrm{~nm}$ to $95 \%$ for the spectral region of $1105-1700 \mathrm{~nm}$. However, the study did not classify different types of botanical foreign matter.

Gamble et al. focused on utilizing fluorescence spectroscopy to determine whether it is possible to quantitatively estimate cotton foreign matter based on their chemical and spectroscopic properties [8]. Extracts of six types of foreign matter (bract, hull, leaf, seed coat, shale, stem) in dimethyl sulfoxide (DMSO) were excited at a single wavelength, producing emission spectra interposed with fluorescence spectra from other foreign matter categories. Results from the partial least-squares (PLS) analysis differentiated hull and leaf due to the presence of a relatively strong emission peak $\left(\mathrm{R}_{\text {hull }}^{2}=0.94, \mathrm{R}_{\text {leaf }}^{2}=0.93\right)$, but the prediction results for bract, seed coat, shale, and stem were poor $\left(R_{\text {bract }}^{2}=0.73, \mathrm{R}_{\text {seedcoat }}^{2}=0.58, \mathrm{R}_{\text {shale }}^{2}=0.43\right.$, $\left.\mathrm{R}_{\text {stem }}^{2}=0.79\right)$.

Compared to the spectroscopy method, the imaging approach provides the information related to color, geometry, and the spatial distribution of the foreign matter. $\mathrm{Xu}$ et al. constructed a cotton trash and cotton measurement (CTCM) system by assembling a video imaging system with the ability to estimate foreign matter content and color parameters of cotton lint samples, but without the ability to differentiate various types of foreign matter [9]. The results of the CTCM were compared to the USDA standards for conventional colorimeters and human classers [10]. High correlations $\left(R^{2}=0.945-0.999\right)$ were reported for color measurements from the CTCM system and those from the HVI, Minolta CR-210 colorimeter, and the grades assigned by human classers. In a later study, the CTCM system was applied to cotton foreign matter differentiation. $\mathrm{Xu}$ et al. examined color features of four common types of foreign matter: bark, leaf, inner side of seed coat, and hairy side of seed coat [11]. For this purpose 400 cotton foreign matter particles from 12 cotton sample were analyzed, and their respective color features used as inputs to three clustering methods (sum of squares, fuzzy clustering, and neural networks). Sum of squares clustering and fuzzy clustering yielded accurate foreign matter classification of $83 \%$ for leaf category and $93 \%$ for bark category, and neural networks had at least $95 \%$ accurate classification rate for all foreign matter categories.

Recently, a system with white light and Ultraviolet (UV) excitation light has shown fluorescence imaging could be a useful tool in cotton foreign matter detection. Zhou et al. constructed a system with the capacity to alternate white light and UV excitation light with the goal of foreign matter detection in the spectral range of $250-850 \mathrm{~nm}$ [12]. A fluorescence spectroscopy study examined optimal excitation and emission spectral range (excitation range $=320$ $400 \mathrm{~nm}$, emission range $=420-600 \mathrm{~nm}$ ) of a single sample of lint containing five foreign matter categories (white bundle strip, black hair, red bundle strip, white paper strip, 
and white woven strip), and indicated the presence of photoexcitable fluorophores. Preliminary results showed fluorescence imaging could possibly be used to detect both white and colored foreign matter. However, the study presented one sample and it only examined non-botanical cotton foreign matter, whereas the majority of the foreign matter in the US cotton is botanical foreign matter.

Cotton foreign matter identification and differentiation methods so far have either considered a limited number of samples or types of foreign matter, and mainly used spectroscopy and color imaging. Hence, there exists a gap when it comes to the consideration of additional types of imaging modalities like fluorescence imaging to cotton foreign matter detection and differentiation, and a larger number of foreign matter categories need to be taken into account.

To fill the knowledge gap, the overall goal of the study was to conduct an in-depth study on fluorescence imaging of both botanical and non-botanical cotton foreign matter detection. Specific objectives were to:

1. explore whether various cotton foreign matter categories contain fluorophores with unique spectral signatures

2. design a fluorescent imaging system and acquire images of cotton foreign matter

3. establish a qualitative criteria to separate cotton foreign matter from lint.

\section{Results}

\section{Fluorescence spectroscopy analysis}

Out of eight botanical foreign matter categories, five (bark, bract, green leaf, brown leaf, stem) had their optimal emission peaks in the red region of the visible spectra ranging from $671 \mathrm{~nm}$ to $675 \mathrm{~nm}$, with optimal excitation wavelengths either at $410 \mathrm{~nm}$ or $430 \mathrm{~nm}$ (Figure 1). The red fluorescence in the aforementioned emission range is due to the presence of chlorophyll. Consequently, the strongest measured emission signal was recorded for green leaves at the peak emission of $675 \mathrm{~nm}\left(2.38 \times 10^{6}\right.$ counts/second (cps)), approximately 148 times stronger than the weakest signal recorded for seed at the emission peak of $461 \mathrm{~nm}(16,000 \mathrm{cps})$.

Seed and seed coat do not have chlorophyll, and therefore no emission in the red spectral range, but are rather optimally excited at $340 \mathrm{~nm}$ and $330 \mathrm{~nm}$, with associated blue emission at $461 \mathrm{~nm}$ and $415 \mathrm{~nm}$, respectively. Hull optimal excitation and emission wavelength is at $400 \mathrm{~nm}$ and $516 \mathrm{~nm}$, and lint is at $360 \mathrm{~nm}$ and $434 \mathrm{~nm}$.

Regarding the non-botanical foreign matter, paper had the strongest emission peak at $3.9 \times 10^{6} \mathrm{cps}$, with optimal excitation and emission wavelength at $360 \mathrm{~nm}$ and 412 $\mathrm{nm}$ (Figure 2). Plastic bale packaging had the same optimal excitation wavelength, but different optimal emission at $434 \mathrm{~nm}$. Plastic bag was optimally excited at $370 \mathrm{~nm}$, with emission peak at $417 \mathrm{~nm}$. Both plastic bale packaging and plastic bag were weakly fluorescent $(8,000$ and 34,000 cps). On the other hand, twine had both optimal excitation and emission wavelength in the UV range $(300 \mathrm{~nm}$ and $356 \mathrm{~nm}$ ) with peak intensity at 482,000 cps. Lint was found to be optimally excited in the UV range at $360 \mathrm{~nm}$, and optimum blue emission at $434 \mathrm{~nm}$.

From the summary of cotton foreign matter categories and lint, their respective optimal excitation and emission peaks, and peak intensities, it can be observed that five botanical foreign matter categories (green leaf, bark, brown leaf, bract, stem) can be excited in the blue spectral range (410 $\mathrm{nm}$ and $430 \mathrm{~nm}$ ) and emit in the red spectral range $(671 \mathrm{~nm}$ to $675 \mathrm{~nm}$ ), with hull optimal excitation at $400 \mathrm{~nm}$ and optimal emission at $516 \mathrm{~nm}$ (Table 1). Two botanical foreign matter categories (seed, seed coat) can be excited in the UV range (330 $\mathrm{nm}$ and $340 \mathrm{~nm}$ ), similar to all four types of non-botanical foreign matter categories, which have optimal excitation wavelengths in the region from $300 \mathrm{~nm}$ to $370 \mathrm{~nm}$. With the exception of twine emitting in the UV region, all foreign matter categories excited in the UV region have their optimal emission peaks in the visible light region.

\section{Fluorescent imaging}

Green fluorescence emission is dominant in all six types of cotton foreign matter (bark, bract, brown leaf, green leaf, hull, stem) and lint excited under blue LED illumination (Figure 3). To a lesser extent, red fluorescence is also present, but in a secondary role. On the other hand, in all types of cotton foreign matter (paper, plastic bag, plastic packaging, seed, seed coat (inner and outer), twine) and lint excited under UV LED illumination, blue fluorescence emission predominates. Paper is a unique case, and because all of its three channels (red, green, blue) are high in value, it appears white.

If any potential classification of cotton foreign matter is to be done, the first step in the image processing sequence is to distinguish foreign matter from lint. By looking at their respective histograms (Figure 4 and Additional files 1, 2 and 3), cotton foreign matter and lint have varying levels of fluorescence emission. Based on those differences, thresholding criteria specific to particular types of foreign matter can be established.

When comparing green leaf and plastic bag to lint, several observations can be made (Figure 4). In the case of green leaf, its red and green channel intensity is lower when compared to the same color channels of lint. When plastic bag is compared to lint, their respective red channels are very close in value. On the other hand, larger difference is found in the green and blue channel where lint exhibited much higher green and blue fluorescence emission. 

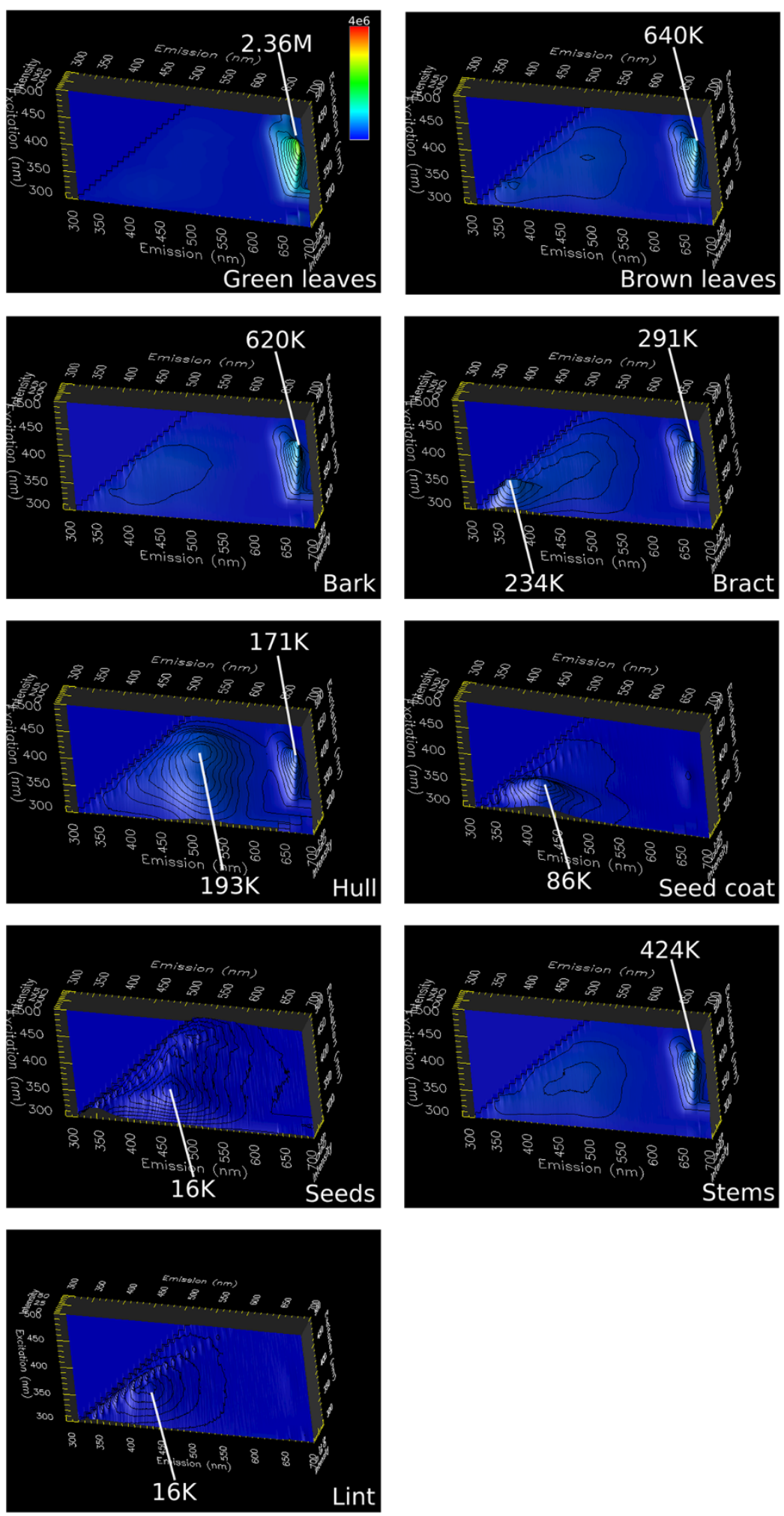

Figure 1 Matrix 3D scans of botanical foreign matter and lint. Five foreign matter categories (bark, brown leaf, bract, green leaf, stem) have the optimal excitation wavelength either at $410 \mathrm{~nm}$ or $430 \mathrm{~nm}$. Their optimal emission wavelength ranges from $671 \mathrm{~nm}$ to $675 \mathrm{~nm}$, and is due to chlorophyll presence. Due to the absence of chlorophyll, seed and seed coat are optimally excited in the UV range ( $340 \mathrm{~nm}$ and $330 \mathrm{~nm}$ ) with optimal emission at $461 \mathrm{~nm}$ and $415 \mathrm{~nm}$, respectively. Hull optimum excitation and emission wavelength is at $400 \mathrm{~nm}$ and $516 \mathrm{~nm}$, and lint's at 360 $\mathrm{nm}$ and $434 \mathrm{~nm}$. 

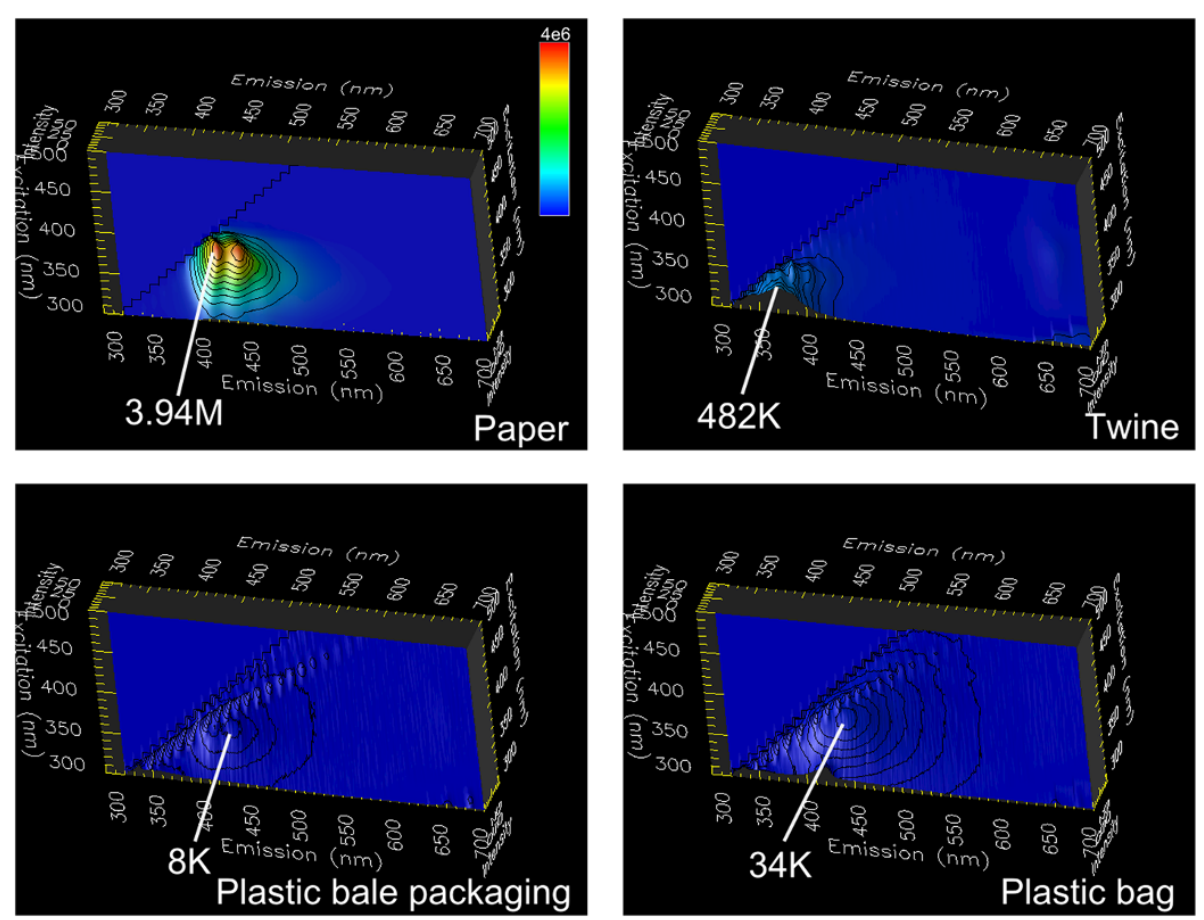

Figure 2 Matrix 3D scans of non-botanical foreign matter. Non-botanical foreign matter categories have their optimal excitation wavelengths in the UV range, with paper and plastic bale packaging at $360 \mathrm{~nm}$, plastic bag at $370 \mathrm{~nm}$, and twine at $300 \mathrm{~nm}$. Twine optimal emission is also in the UV range $(356 \mathrm{~nm})$, while those of paper, plastic bale packaging, and plastic bag are in the visible light range at 412, 434, and $417 \mathrm{~nm}$, respectively.

In general, studies focused on detection and differentiation of cotton foreign matter have typically used white light as a source of illumination. To show how fluorescence emission differs from white light reflectance, a comparison can be made (Table 2). For six types of

Table 1 Optimal excitation and emission wavelength, and their associated intensities for botanical foreign matter, non-botanical foreign matter, and lint

\begin{tabular}{|c|c|c|c|}
\hline Category & $\begin{array}{c}\text { Optimal } \\
\text { excitation } \lambda \\
(n m)\end{array}$ & $\begin{array}{l}\text { Optimal } \\
\text { emission } \lambda \\
\quad(n m)\end{array}$ & $\begin{array}{c}\text { Intensity } \\
\left(\times 10^{3}\right) \\
\text { (cps) }\end{array}$ \\
\hline Bark & 430 & 672 & 620 \\
\hline Bract & 430 & 672 & 291 \\
\hline Brown Leaf & 430 & 672 & 640 \\
\hline Green Leaf & 410 & 675 & 2,360 \\
\hline Hull & 400 & 516 & 193 \\
\hline Seed & 340 & 461 & 16 \\
\hline Seed Coat & 330 & 415 & 86 \\
\hline Stem & 430 & 671 & 424 \\
\hline Paper & 360 & 412 & 3,940 \\
\hline Plastic Bag & 370 & 417 & 34 \\
\hline Plastic Bale Packaging & 360 & 434 & 8 \\
\hline Twine & 300 & 356 & 482 \\
\hline Lint & 360 & 434 & 16 \\
\hline
\end{tabular}

botanical cotton foreign matter (bark, bract, brown leaf, green leaf, hull, stem) imaged under the blue LED excitation light and white light, lint in general (with the exception of hull) has higher pixel intensity values in all three channels. A similar pattern can be observed for cotton foreign matter imaged under the UV LED excitation light and white light (seed coat, seed, twine), where lint is dominant in most color channels. Paper has higher signal in all three color channels in comparison to lint. Lint exhibited stronger blue and green fluorescence emission than plastic bag and plastic packaging, respectively. However, when imaged under white light, lint has stronger red and green reflectance intensity than plastic bag, and stronger blue reflectance than plastic packaging.

\section{Discussion}

According to the spectroscopic analysis results, five out of eight botanical foreign matter categories exhibited red fluorescence emission in the range from $671 \mathrm{~nm}$ to $675 \mathrm{~nm}$. Fluorescence emission in the particular wavelength range can be attributed to the presence of chlorophyll, a green pigment typically found in chloroplasts of green plants, and the leaf mesophyll cells [13]. In contrast, fluorescent images of bark, bract, brown leaf, and stem exhibited mainly green fluorescence. Specifically, we observed fluorescence primarily in the blue-green range, at $\lambda_{e m}=461$ $\mathrm{nm}$ for seeds and $\lambda_{e m}=415 \mathrm{~nm}$ for seed coat, and hull 

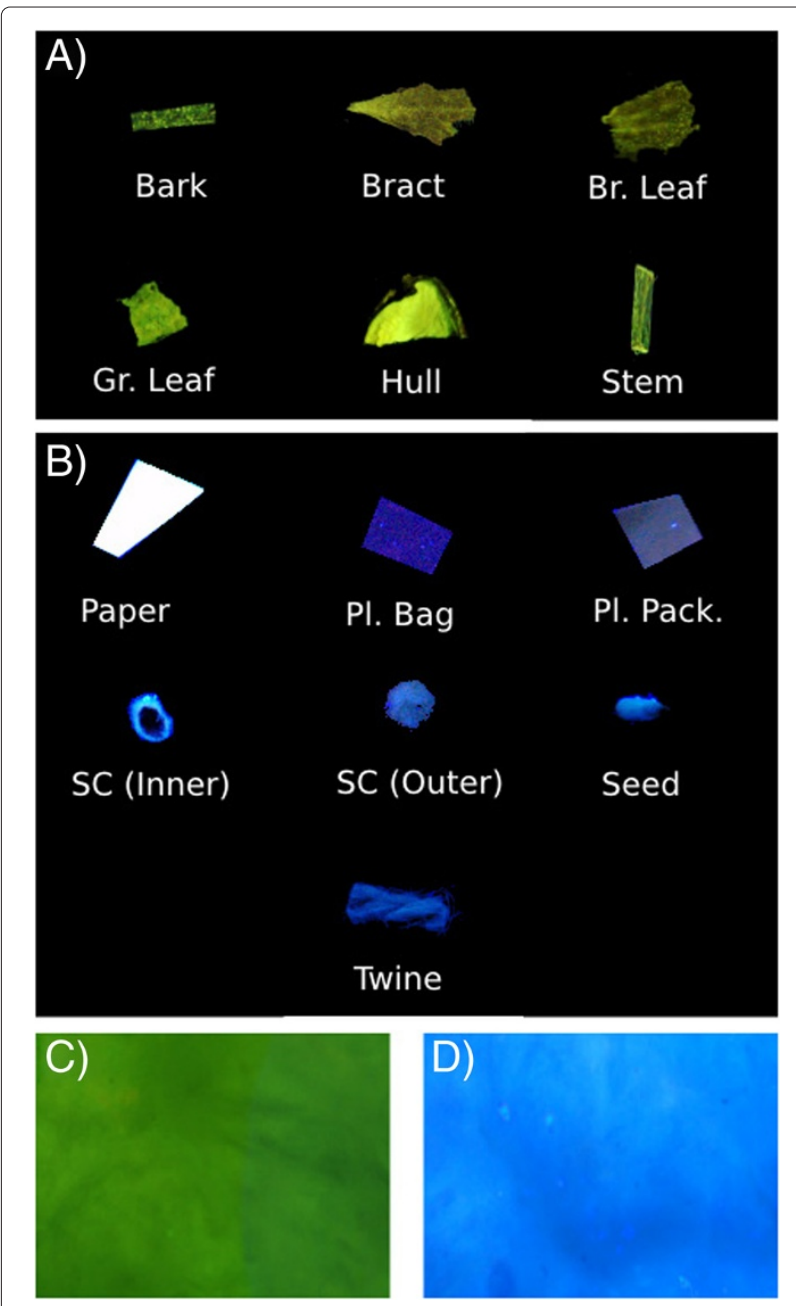

Figure 3 A total of 13 types of cotton foreign matter and lint illuminated with blue LED and UV LED light. A) 6 types of cotton foreign matter illuminated with UV LED light. B) 7 types of cotton foreign matter illuminated with UV LED light. C) Lint illuminated with blue LED light. D) Lint illuminated with UV LED light.

emitted in the green emission range $\left(\lambda_{e m}=516 \mathrm{~nm}\right)$. In some cases, such as brown leaf and stems, chlorophyll fluorescence diminishes over time as the chloroplasts degrade and the green fluorophores become more prominent [14]. In other cases (i.e., bark, bract, stem), the absence of chlorophyll emission is related to the absence or low density of chloroplasts, making the green fluorescence component prominently detectable. The source for the blue-green fluorescence emission ( $400 \mathrm{~nm}$ to $560 \mathrm{~nm}$ ) in foreign matter categories originating from the cotton plant can be traced back to the several UV-excitable fluorescing pigments, namely ferulic acid, cinnamic acid, and flavonoids [14]. Ferulic acid is derived from cinnamic acid, and both are found in cell walls, while flavonoid is found in plant vacuoles [15]. In contrast, research by Gamble et al. showed the strongest emission for hull, followed by bract, leaf, and seed coat, and lowest for stem [8]. The aforementioned study used only single excitation wavelength at which the emission spectra of cotton foreign matter (with the exception of hull and leaf) overlapped significantly.

Of the four non-botanical foreign matter categories subjected to fluoroscopic analysis, paper had the strongest emission signal in the blue range $\left(\lambda_{e m}=412 \mathrm{~nm}\right)$. The strong signal can be attributed to the presence of fluorescent whitening agents used during chemical processing of wood pulp in order to alter its color. Twine is spun from fibers made from jute, a plant commonly used to make rope and cloth for industrial use. Jute fibers emit fluorescence under excitation due to the pigments and lignin found in the cell walls [16]. Two other non-botanical foreign matter categories, plastic bag and plastic bale packaging, exhibit fluorescence emission in the blue range $\left(\lambda_{\text {em }}=417 \mathrm{~nm}\right.$ and $\left.434 \mathrm{~nm}\right)$ due to the presence of coloring pigments [17]. It should be noted all non-botanical foreign matter categories achieved better optimum emission under the UV LED light, and with the exception of seed and seed coat, botanical foreign matter categories containing chlorophyll achieved better optimum emission under the blue LED light. Since cotton foreign matter is typically found admixed with lint, it is necessary to consider its optimal blue emission band so foreign matter can be segmented out.

Since different types of foreign matter have varying fluorescence emission bands, it is advantageous to look at different channels extracted from fluorescence images. Botanical cotton foreign matter possesses large amount of chlorophyll, thus causing them to emit red fluorescence. However, the red fluorescence changes over time, as cotton plant parts age after they are harvested. The change is typically not uniform, and depends on the cellular process following cell death which determine its degeneration. In this instance, it could be beneficial to focus on the green fluorescence emission caused by additional pigments found in cotton plant (ferulic and cinnamic acid, flavonoids) [14]. Botanical foreign matter categories (seed and seed coat), and non-botanical foreign matter categories (twine, plastic bag, and plastic packaging) do not contain a strong red fluorescence emission, but do contain other fluorescence emitting agents in the green and blue spectral region. The focus on red channel of the color images could be beneficial in foreign matter segmentation from lint, and potential classification between botanical and non-botanical cotton foreign matter. Another source of potentially useful information would be to explore other color models like HSV, in which the illumination component can be separated, and as a result, sources of illumination fluctuations minimized. Color measurements are less likely to change unlike geometric features which change due to the fragility of foreign matter particles being broken into smaller pieces [11]. In the same 

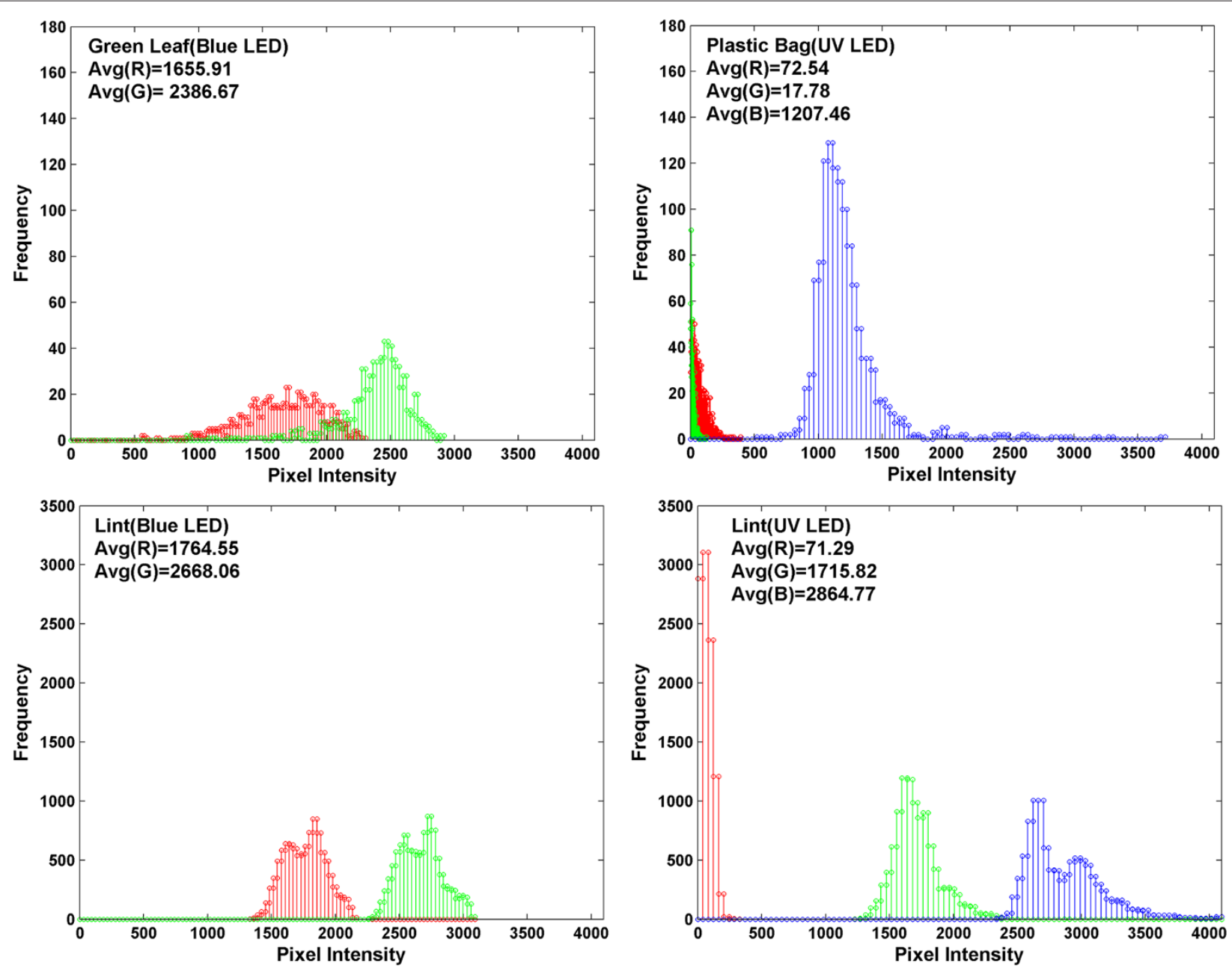

Figure 4 Examples of histograms of cotton foreign matter and lint. Two categories of cotton foreign matter shown are green leaf and plastic bag, in addition to lint (for others see Additional files 1, 2 and 3).

study, a color imaging system capable of detecting and classifying four categories of botanical foreign matter (bark, leaf, and seed coat) based on their color features was developed. In the current study focus was on exploring whether fluorescence imaging can provide fluorescence emission in the visible spectra which can potentially be used for classification of cotton foreign matter in future studies.

A critical step in the detection of foreign matter in images of lint is the segmentation of the image. In this study we used manual thresholding and supervised application of morphological operators, because the main goal of this study is the determination of the additional information gained by fluorescence imaging. Clearly, supervised segmentation is subject to intra- and inter-observer variability, and an unsupervised method would be desirable. In fact, the images contain a large amount of information that can be used for the future development of unsupervised segmentation methods. One useful assumption is spatial connectivity that allows the use of region-based methods. Second, with images obtained under different lighting conditions, multidimensional thresholding is possible. Third, the widely inhomogeneous illumination advertises the application of further image enhancement (specifically, homomorphic filtering) and the application of locally adaptive thresholding. The development of unsupervised segmentation methods will be subject of further study.

Fluoroscopic analysis of samples necessitated the breakdown of samples with a strong solvent in order to dissolve it thoroughly. Therefore, the total amount of fluorophores detected with spectroscopy is much higher than the amount detected in images because fluorescence signal in images is from surface images. Also, the signals in botanical foreign matter can vary over time because cellular degradation lowers the amount of fluorophores 
Table 2 Average intensity of lint compared to cotton foreign matter categories with respect to the individual color channels from images under blue LED, UV LED, and white light illumination

\begin{tabular}{|c|c|c|c|}
\hline Category & Blue LED & UV LED & White light \\
\hline Bark, Bract, & Lint has higher & - & Lint has higher red, green, \\
\hline Brown leaf, & red and green & - & and blue reflectance \\
\hline Green leaf, & fl. emission & - & \\
\hline Stem & & - & \\
\hline \multirow[t]{3}{*}{ Hull } & Lint has higher & - & \multirow{3}{*}{$\begin{array}{l}\text { Lint has higher red, green, } \\
\text { and blue reflectance }\end{array}$} \\
\hline & green fl. & - & \\
\hline & emission & - & \\
\hline \multirow[t]{2}{*}{ Paper } & - & Lint has lower red, green & \multirow{2}{*}{$\begin{array}{c}\text { Lint has lower red, green } \\
\text { and blue reflectance }\end{array}$} \\
\hline & - & and blue fl. emission & \\
\hline \multirow[t]{2}{*}{ Plastic bag } & - & Lint has higher green and & \multirow{2}{*}{$\begin{array}{l}\text { Lint has higher red and } \\
\text { green reflectance }\end{array}$} \\
\hline & - & blue fl. emission & \\
\hline Plastic bale & - & \multirow{2}{*}{$\begin{array}{l}\text { Lint has higher green and } \\
\text { blue fl. emission }\end{array}$} & \multirow{2}{*}{$\begin{array}{l}\text { Lint has higher blue } \\
\text { reflectance }\end{array}$} \\
\hline Packaging & - & & \\
\hline Seed coat (Inner), & - & \multirow{3}{*}{$\begin{array}{c}\text { Lint has higher green and } \\
\text { blue fl. emission }\end{array}$} & \multirow{3}{*}{$\begin{array}{c}\text { Lint has higher red, green, } \\
\text { and blue reflectance }\end{array}$} \\
\hline Seed coat (Outer), & - & & \\
\hline Seed, Twine & - & & \\
\hline
\end{tabular}

gradually. In contrast smaller changes can be expected for non-botanical foreign matter like paper and plastic. In this study, the fluorescence images were acquired one month after the spectroscopy experiment was done because the optimal excitation and emission wavelengths must be first identified from the spectroscopy data before optical imaging system can be set up. This resulted in the difference between the spectroscopic and the imaging results.

\section{Conclusions}

Excitation in the UV and blue light spectral range induced a fluorescence emission signal for each individual foreign matter categories under consideration. For some of them emission peaks overlapped, however their peak intensity varied. Fluorescence spectroscopy results separate cotton foreign matter categories into two groups according to the types of optimal excitation light used to induced optimum fluorescence emission.
The blue LED light provided optimum excitation light for bark, brown leaf, bract, green leaf, hull, and stem, while the UV LED light provided optimum excitation light for paper, plastic bag, plastic packaging, seed, seed coat, and twine. An imaging apparatus containing blue and UV LED excitation sources was integrated to examine the feasibility of using fluorescence imaging to detect cotton foreign matter. The results showed that fluorescent imaging is a promising tool to detect cotton foreign matter on the surface of cotton lint. Future studies will focus on improving the image analysis process and to classify cotton foreign matter categories.

\section{Methods}

\section{Sample preparation}

For fluorescence spectroscopy analysis and fluorescence imaging, two types of cotton foreign matter samples were collected and analyzed: botanical and non-botanical foreign matter (Figure 5). Botanical cotton foreign matter

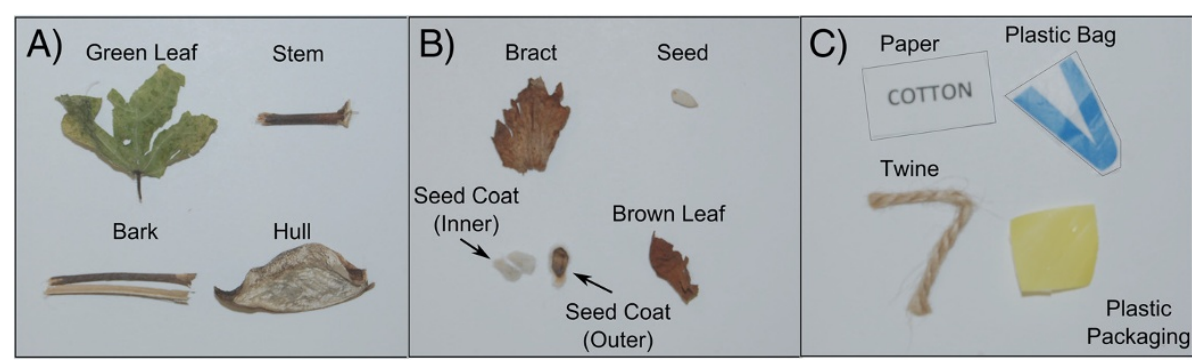

Figure 5 Cotton foreign matter categories used in this study. Panels $\mathbf{A}$ (green leaf, stem, bark, hull) and $\mathbf{B}$ (bract, seed, seed coat (inner), seed coat (outer), brown leaf) show botanical foreign matter categories, and Panel C (paper, plastic bag, twine, plastic bale packaging) shows non-botanical foreign matter categories. 
samples were collected from seed cotton of four cotton cultivars from the Fall 2012 harvest: Delta Pine 0912, Delta Pine 1050, PhytoGen 499, and FiberMax 1944. Individual botanical foreign matter categories (bark, bract, green leaf, brown leaf, stem, hull, seed, seed coat) were extracted from seed cotton manually, and ground for 90s with an 8000M Mixer/Mill (SPEX SamplePrep, Metuchen, $\mathrm{NJ}$ ). At the time of analysis, it had been four months since the cotton samples were harvested from the field. Nonbotanical foreign matter categories of paper, twine, and plastic bag were purchased from local stores, while plastic bale packaging was obtained from the cotton gin in Tifton, $\mathrm{GA}$, and all were cut into smaller pieces $(\sim 2 \times 2 \mathrm{~mm})$ with scissors.

\section{Fluorescence spectroscopy}

A total $0.05 \mathrm{~g}$ of individual cotton foreign matter categories were extracted with $10 \mathrm{ml}$ of DMSO for 2 hours at room temperature. Extraction was followed by filtering (Whatman 42, $2.5 \mu \mathrm{m}$ ), 2:1 dilution with DMSO, and pipetting $3.5 \mathrm{ml}$ of the solution into a glass cuvette (Starna Cells, Inc., Atascadero, CA), which was then placed into the sample holder of a fluorospectrometer (Fluoromax 3, Horiba, Edison, NJ). Matrix scans were obtained in the excitation range of 300-500 nm, emission range of 320$700 \mathrm{~nm}$, with $0.5 \mathrm{~s}$ integration time, $2 / 2$ slits, and figures drawn with OpenDX [18].

\section{Fluorescent imaging apparatus}

The fluorescent imaging apparatus (Figure 6) consisted of an optical breadboard (Performance Series, $24^{\prime \prime} \times 18^{\prime \prime} \times$ 2.4" $(\mathrm{L} \times \mathrm{W} \times \mathrm{T})$, Thorlabs Inc., Newton, NJ), two types of excitation sources used exclusive of each other: two blue LEDs, and a UV LED array. For reference purpose additional white light source was also used. When LEDs (Royal Blue Mounted High Power LEDs, nominal $\lambda=455 \mathrm{~nm}$, $1600 \mathrm{~mA}$, Thorlabs Inc., Newton, NJ) were used as excitation sources, light intensity was controlled by two T-cube LED drivers (1200 mA, Thorlabs Inc., Newton, NJ), and power provided by two $15 \mathrm{~V}$ power supplies for T-cubes (Thorlabs Inc., Newton, NJ). A bandpass filter $(\mathrm{CWL}=$ $450 \mathrm{~nm}, 40 \mathrm{~nm}$ bandpass, Thorlabs Inc., Newton, NJ) was positioned in front of each blue LED to reduce the spectral bandwidth of the emission light. A $500 \mathrm{~nm}$ longpass filter (cut-off $\lambda=500 \mathrm{~nm}$, Thorlabs Inc., Newton, NJ) was placed in front of the SLR camera to avoid the spectral overlap with the fluorescence excitation of samples under observation.

When the UV LED was used $(\lambda=370 \mathrm{~nm}$, Edmund Optics, Barrington, NJ), a $400 \mathrm{~nm}$ shortpass filter (Edmund Optics, Barrington, NJ) was placed in front of it, and a $400 \mathrm{~nm}$ longpass filter (cut-off $\lambda=400 \mathrm{~nm}$, Thorlabs Inc., Newton, NJ) in front of the camera lens instead of the $500 \mathrm{~nm}$ longpass filter used in combination with the blue LEDs. When the white light tungsten halogen source was utilized (JCD, GX6503A), the longpass

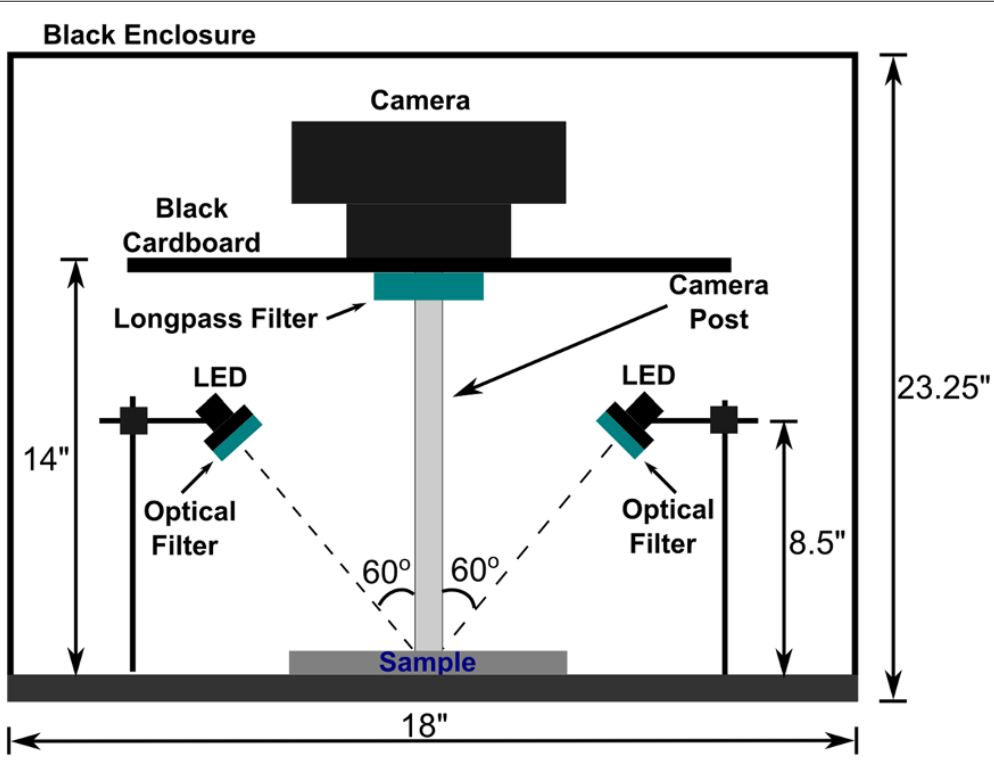

Figure 6 Side view of the fluorescent imaging apparatus. Excitation light was provided by two blue LEDs placed at a $60^{\circ}$ angle with respect to the camera post in order to homogeneously illuminate the sample under observation, and each equipped with an optical filter in front of it to prevent spectral overlap. An SLR camera with a $500 \mathrm{~nm}$ longpass filter was positioned above the sample. The entire apparatus was enclosed in a lightproof enclosure. When other excitation sources were used (UV, white light), the blue LEDs and its bandpass filters were removed, and in the case of UV LED a $400 \mathrm{~nm}$ shortpass filter positioned in front of the LED, and a $400 \mathrm{~nm}$ longpass filter in front of the SLR camera. 
filter positioned in front of the camera was removed, since there was no need to reduce the spectral overlap. Images under white light illumination were used for comparison purposes, while blue LED and UV LED light was used to provide excitation light for fluorescent images.

Cotton samples were centrally positioned on the optical breadboard while the LEDs were mounted on posts adjacent to the sample in order to provide a homogeneous excitation light to the samples under observation. A digital SLR camera (D40, Nikon Inc., Melville, NY) was mounted on a camera stand (Nikon Inc., Melville, NY) vertically above the sample and black cardboard with a hole in the center attached to it block the background fluorescence. The entire fluorescent imaging setup was enclosed and covered with black non-fluorescent cloth to exclude ambient light.

Images were acquired with an $\mathrm{f} / 5.6$ aperture and exposure time of $6 \mathrm{~s}$ (under blue LED excitation), $1.6 \mathrm{~s}$ (under UV light excitation), 1/15 s (under white light illumination), while camera sensitivity was kept at ISO 400. Three different exposure times were used for different types of illumination in order to prevent image saturation. Raw NEF (Nikon Electronic Format) images were converted to 16 bit TIFF images with UFRaw (http://ufraw.sourceforge. net). Images were denoised and binned $(4 \times 4)$ to $759 \times 503$ pixels with Crystal Image, a quantitative image analysis software [18]. Further denoising was performed by additional applications of a median and a generalized Gaussian filter.

To compare the red, green, and blue intensities of images taken under the blue LED, UV LED, and white light illumination, five replicates of each type of foreign matter was imaged once under each source of illumination. A fixed, but image-dependent, threshold was used to separate the brightly fluorescent lint from the more weaklyfluorescent foreign-matter regions. This step resulted in a binary mask that contained binary zeros corresponding to lint pixels and binary ones corresponding to foreign mater pixels. In some cases, morphological operations (morphological opening, cluster labeling with a cluster size filter) were applied to the binary mask. The clusters of binary ones effectively acted as regions of interest (ROI) for the foreign matter, thereby effectively separating foreign matter from the lint. The average intensity in the foreign-matter regions was then calculated and compared to the average intensity of the lint layer.

\section{Additional files}

Additional file 1: Figure S1. Histograms of 13 types of cotton foreign matter and lint imaged under white light.

Additional file 2: Figure S2. Histograms of 7 types of cotton foreign matter and lint imaged under UV LED light.
Additional file 3: Figure S3. Histograms of 6 types of cotton foreign matter and lint imaged under blue LED light.

Competing interests

The authors declare that they have no competing interests.

\section{Authors' contributions}

AM performed analysis of spectroscopic and fluorescent imaging data, and contributed to writing. CL contributed to experimental design and writing. $\mathrm{MH}$ contributed to analysis of spectroscopic data. All authors read and approved the final manuscript.

\section{Acknowledgements}

The work was supported by the funding from the Georgia Cotton Commission and the Cotton Incorporated. The authors gratefully acknowledge Andy Knowlton (Research Engineer/Gin Manager) at the UGA Cotton Micro Gin in Tifton, GA, for kindly providing us with cotton lint and cotton foreign matter samples.

\section{Author details}

${ }^{1}$ College of Engineering, University of Georgia, 712F Boyd Graduate Research and Studies Center, 30602 Athens, GA, USA. ${ }^{2}$ College of Engineering, University of Georgia, Driftmier Engineering Center, 30602 Athens, GA, USA.

Received: 11 July 2014 Accepted: 15 October 2014

Published: 1 December 2014

\section{References}

1. Wakelyn PJ, Bertoniere NR, French AD, Thibodeaux DP, Triplett BA, Rousselle M-A, Goynes WRJr, Edwards JV, Hunter L, McAlister DD, Gamble GR: Cotton Fiber Chemistry and Technology. Boca Raton: CRC Press; 2010

2. Fortier C, Rodgers J, Foulk J: Investigation of the impact of instrumental and software applications on cotton and botanical trash identification by ultraviolet-visible and near-infrared spectroscopy. J Cotton Sci 2011, 15:170-178.

3. Lieberman MA, Bragg CK, Brennan SN: Determining gravimetric bark content in cotton with machine vision. Textil Res J 1998, 68(2):94-104.

4. Himmelsbach DS, Hellgeth JW, McAlister DD: Development and use of an attenuated total reflectance/fourier transform infrared (ATR/FT-IR) spectral database to identify foreign matter in cotton. J Agric Food Chem 2006, 54(20):7405-7412.

5. Fortier CA, Rodgers JE, Cintron MS, Cui X, Foulk JA: Identification of cotton and cotton trash components by fourier transform near-infrared spectroscopy. Textil Res J 2011, 81(3):230-238.

6. Fortier C, Rodgers J, Foulk J, Whitelock D: Near-infrared classification of cotton lint, botanical and field trash. J Cotton Sci 2012, 16(1):72-79.

7. Liu Y, Foulk J: Potential of visible and near infrared spectroscopy in the determination of instrumental leaf grade in lint cottons. Textil Res J 2013, 83(9):928-936.

8. Gamble GR, Foulk JA: Quantitative analysis of cotton (gossypium hirsutum) lint trash by fluorescence spectroscopy. J Agric Food Chem 2007, 55(13):4940-4943.

9. Xu B, Fang C, Huang R, Watson MD: Chromatic image analysis for cotton trash and color measurements. Textil Res $J$ 1997, 67 (12):881-890.

10. Xu B, Fang C, Huang $R$, Watson M: Cotton color measurements by an imaging colorimeter. Textil Res J 1998, 68(5):351-358.

11. Xu B, Fang C, Watson M: Clustering analysis for cotton trash classification. Textil Res J 1999, 69(9):656-662.

12. Zhou F, Ding T: Detection of cotton lint trash within the ultraviolet-visible spectral range. App/ Spectrosc 2010, 64(8):936-941.

13. DeEll JR, van Kooten O, Prange RK, Murr DP: Applications of chlorophyll fluorescence techniques in postharvest physiology. Hort Rev 1999, 23:69-107.

14. Buschmann C, Lichtenthaler HK: Principles and characteristics of multi-colour fluorescence imaging of plants. J Plant Physiol 1998, 152(2):297-314

15. Daniel M, Purkayastha R: Handbook of Phytoalexin Metabolism and Action Vol. 37. New York: CRC Press; 1995 
16. Khan $F$, Ahmad S: Chemical modification and spectroscopic analysis of jute fibre. Polymer Degrad Stabil 1996, 52(3):335-340.

17. Espi E, Salmeron A, Fontecha A, García Y, Real A: Plastic films for agricultural applications. J Plastic Film Sheeting 2006, 22(2):85-102.

18. Haidekker M: Advanced Biomedical Image Analysis. Hoboken: John Wiley \& Sons; 2011.

doi:10.1186/1754-1611-8-29

Cite this article as: Mustafic et al.: Blue and UV LED-induced fluorescence in cotton foreign matter. Journal of Biological Engineering 2014 8:29.

Submit your next manuscript to BioMed Central and take full advantage of:

- Convenient online submission

- Thorough peer review

- No space constraints or color figure charges

- Immediate publication on acceptance

- Inclusion in PubMed, CAS, Scopus and Google Scholar

- Research which is freely available for redistribution

Submit your manuscript at www.biomedcentral.com/submit
C Biomed Central 